\title{
Microstructures and Mechanical Properties of Laser-Sintered Commercially Pure Ti and Ti-6Al-4V Alloy for Dental Applications
}

\author{
Yoshimitsu Okazaki ${ }^{1, *(\mathbb{D})}$ and Akira Ishino ${ }^{2}$ (D) \\ 1 Department of Life Science and Biotechnology, National Institute of Advanced Industrial Science and \\ Technology, 1-1 Higashi 1-chome, Tsukuba, Ibaraki 305-8566, Japan \\ 2 IDS Co. Ltd., 3-5-4 Hongo, Bunkyo-ku, Tokyo 113-0033, Japan; a-isino@idscoltd.jp \\ * Correspondence: y-okazaki@aist.go.jp; Tel.: +81-29-861-7179
}

Received: 21 November 2019; Accepted: 21 January 2020; Published: 29 January 2020

\begin{abstract}
To apply laser-sintered titanium (Ti) materials to dental prostheses with a three-dimensional structure such as partial dentures, we examined the microstructures and mechanical properties of commercially pure (CP) Ti grade $(\mathrm{G}) 2$ annealed after laser sintering and laser-sintered (as-built) Ti-6Al-4V alloy. The tensile and fatigue properties of CP Ti G 2 annealed at $700{ }^{\circ} \mathrm{C}$ for $2 \mathrm{~h}$ after laser sintering were close to those of wrought $\mathrm{CP}$ Ti G 2 annealed at the same temperature after hot forging. The ultimate tensile strengths $\left(\sigma_{\mathrm{UTS}}\right)$ of $90^{\circ}$ - and $0^{\circ}$-direction-built $\mathrm{CP}$ Ti G 2 rods after laser sintering 10 times were 553 and $576 \mathrm{MPa}$ and the total elongations (TE) of these rods were $26 \%$ and $28 \%$, respectively. The fatigue strengths $\left(\sigma_{\mathrm{FS}}\right)$ at $10^{7}$ cycles of the $90^{\circ}$ - and $0^{\circ}$-direction-built CP Ti G 2 rods after laser sintering 10 times were $\sim 320$ and $\sim 365 \mathrm{MPa}$, respectively. The ratio $\sigma_{\mathrm{FS}} / \sigma_{\mathrm{UTS}}$ was in the range of 0.5-0.7. The changes in the chemical composition and mechanical properties after laser sintering 10 times were negligible. The fatigue strength of the laser-sintered Ti-6Al-4V alloy was $\sim 600 \mathrm{MPa}$, which was close to that of wrought Ti-6Al-4V alloy. These findings indicate that the laser-sintered CP Ti and Ti-6Al-4V alloy can also be applied in dental prostheses similarly to laser-sintered $\mathrm{Co}-\mathrm{Cr}-\mathrm{Mo}$ alloy. In particular, it was clarified that laser sintering using CP Ti G 4 powder is useful for dental prostheses.
\end{abstract}

Keywords: titanium materials; laser sintering; microstructure; tensile property; fatigue property; physical property; dental prostheses

\section{Introduction}

Metallic materials such as titanium (Ti) materials and cobalt-chromium-molybdenum (Co-Cr-Mo) alloys with excellent mechanical properties and structural stability have been widely used for dental prostheses (especially metal frames for partial dentures, complete dentures, and implant superstructures) [1-3]. Ti materials (commercially pure (CP) Ti and Ti alloys) with high biocompatibility have been widely used for orthopedic implants and dental prostheses. CP Ti for orthopedic implants is classified into grades $(\mathrm{G}) \mathrm{G} 1(\mathrm{O} \leq 0.18$ mass $\%), \mathrm{G} 2(\mathrm{O} \leq 0.25$ mass $\%), \mathrm{G} 3(\mathrm{O} \leq 0.35$ mass \%), and $\mathrm{G}$ $4(\mathrm{O} \leq 0.4$ mass \%) in International Organization for Standardization (ISO) 5832-2 [4]. As the grade of $\mathrm{CP} \mathrm{Ti}$ increases, the amount of trace elements such as oxygen $(\mathrm{O})$ increases.

$\mathrm{Ti}-6 \% \mathrm{Al}-4 \% \mathrm{~V}$ alloy (here and hereafter values of alloy compositions indicate mass \%) is also widely used in the medical field and is standardized in ISO 5832-3 [5]. Since the O concentration in laser-sintered Ti-6Al-4V alloy increases upon laser sintering [6], high-purity Ti-6Al-4V G 5 powder for additive manufacturing (AM) has been standardized in ASTM F 2924 [7]. The O concentration in this standard is defined according to the particle size of the Ti-6Al-4V alloy powder. In the Ti alloys 
containing $\mathrm{Al}$, the $\mathrm{O}$ concentration is limited to $\leq 0.2 \%$ [5]. On the other hand, since CP Ti does not contain $\mathrm{Al}$, it is expected that the $\mathrm{O}$ concentration can be increased to $0.4 \%$ as standardized in ISO 5832-2 [4]. Ti materials have the advantage of being lower in density and lighter than Co-Cr-Mo alloys. Dental prostheses (metal frames for partial dentures, complete dentures, and implant superstructures) fabricated using Ti materials are also suitable for patients sensitive to Co ions released from $\mathrm{Co}-\mathrm{Cr}-\mathrm{Mo}$ alloys [2].

The mechanical properties of dental-cast CP $\mathrm{Ti}$ and $\mathrm{Ti}$ alloys have been reported [8-10]. In conventional dental casts with Ti materials, a brittle (hard) surface oxide (alpha-case) layer and blow holes in the central part of casts are formed owing to the reaction of Ti materials with the mold material during the casting process. These casting defects cause problems such as the breakage of partial dentures and clasps. This hard alpha-case layer has also made it difficult to adapt Ti materials to crowns, bridges, and so forth [11,12]. In the case of using a computer-aided machining (CAM) milling system, it is difficult to manufacture complicated shapes, and long processing times are required [2]. Therefore, AM is expected to be a new technology for manufacturing Ti dental prostheses. In the AM of Ti materials, since no investment mold material is used, no reaction occurs between the mold material and the Ti material. Thus, as Ti has a strong affinity to $\mathrm{O}$, for the AM of Ti materials, it is important to examine the change in the $\mathrm{O}$ concentration of Ti materials after laser sintering. However, there have been few studies on the mechanical and microstructural properties of laser-sintered CP Ti and Ti-6Al-4V alloys for dental prostheses. In particular, there are few reports on the fatigue properties of laser-sintered Ti materials.

To obtain regulatory approval for dental prostheses and orthopedic devices produced by 3-D layer manufacturing in Japan, evaluation of the chemical composition, powder recycling, melting point, microstructure, tensile property, immersion property, and fatigue property is desirable [1]. We acquired experimental data according to these requirements for regulatory approval in dental prostheses.

The microstructures and mechanical properties of laser-sintered $\mathrm{Co}-\mathrm{Cr}-\mathrm{Mo}$ alloys for dental prostheses have been investigated [1-3]. These days, the tensile and fatigue properties of Co-25Cr-5Mo-5W (SP2) and W-free Co-28Cr-6Mo alloys are extremely superior to those of conventional dental-cast Co-Cr-Mo alloys [1]. The ultimate tensile strength $\left(\sigma_{\mathrm{UTS}}\right)$ and total elongation (TE) of Co-28Cr-6Mo alloys are close to those of hot-forged Co-28Cr-6Mo alloys. The fatigue strengths $\left(\sigma_{\mathrm{FS}}\right)$ at $10^{7}$ cycles of the $90^{\circ}$ - and $0^{\circ}$-direction-built Co-28Cr-6Mo alloys are $\sim 500$ and $\sim 600 \mathrm{MPa}$, respectively [1]. These superior mechanical properties result from the precipitation of fine intermetallic compound $\pi$-phase (lattice parameter $\mathrm{a}=\mathrm{b}=\mathrm{c}=0.633 \mathrm{~nm}$ ) particles in the grains and grain boundaries of the fine face-centered-cubic (fcc) matrix formed owing to rapid solidification [1]. The changes in the chemical composition and mechanical properties of Co-25Cr-5Mo-5W and Co-28Cr-6Mo alloys after laser sintering 20 times are also negligible.

In this study, we investigated the chemical composition, immersion property, microstructure, tensile property, and fatigue strength of CP Ti G 2 annealed at $700{ }^{\circ} \mathrm{C}$ for $2 \mathrm{~h}$ after laser sintering for dental application with 3-D structures (metal frames for partial dentures, complete dentures, and implant superstructures). The purpose of this study was to compare the mechanical properties of laser-sintered Ti materials with those of laser-sintered Co-Cr-Mo alloy. To develop dental prostheses with high strength, these properties were also compared with those of laser-sintered (as-built) Ti-6Al-4V alloy.

Moreover, to obtain similar two-phase equiaxed grains of the alpha $(\alpha)$-phase [hexagonal-close-packed (hcp) structure] and beta ( $\beta$ )-phase [body-centered-cubic (bcc) structure] as the wrought Ti-6Al-4V alloy [13], the effect of the heat treatment temperature on as-built Ti-6Al-4V alloy rods was also investigated.

In particular, we focused on the fatigue properties of laser-sintered and wrought Ti materials. The results obtained in this study are expected to be useful for the development of Ti dental prostheses by 3-D layer manufacturing. 


\section{Experimental Procedure}

\subsection{Test Specimens}

\subsubsection{Laser Sintering and Dental Casting}

CP Ti G 2 (EOS (EOS GmbH Electro Optical System, Krailling, Germany) and TILOP (Osaka Titanium Technologies Co., Ltd., Osaka, Japan) powders were prepared by plasma and Ar gas atomization processes, respectively. The CP Ti G 2 powder was laser-sintered using a system comprising an EOS M290 or EOS M270 machine ((EOS GmbH Electro Optical System, Krailling, Germany), EOSPRINT v. 1.3 (EOS GmbH Electro Optical System, Krailling, Germany) and HCS v. 2.3.29 software (EOS GmbH Electro Optical System, Krailling, Germany), and the TiCP $30 \mu \mathrm{m}$ FlexLine parameter set. Ti-6Al-4V (EOS) alloy powder and a CP Ti G 2 ingot for preparing conventional dental casts were used for comparison. The Ti-6Al-4V alloy powder was laser-sintered in an Ar atmosphere using a system comprising an EOS M290 machine, EOSPRINT v. 1.5 and HCS v. 2.4.14 software, and the Ti64 Performance M291 1.10 parameter set.

The laser beam power $(\mathrm{P})$ and the hatch spacing between scan passes $(\mathrm{H})$ were 150-300 W (mainly 280-300 W) and 0.1-0.15 mm (mainly $0.13-0.14 \mathrm{~mm}$ ), respectively. The laser scan speed (V) and powder stacking (deposited layer) thickness (T) were fixed from 1000 to $1300 \mathrm{~mm} / \mathrm{s}$ (mainly 1200-1300 mm/s) and $0.02-0.04 \mathrm{~mm}$ (mainly $0.03 \mathrm{~mm}$ ), respectively. The laser spot focus diameter was from 0.1 to $0.3 \mathrm{~mm}$ (mainly $0.1 \mathrm{~mm}$ ). The volumetric energy density $(\mathrm{E})=\mathrm{P} /(\mathrm{H} \cdot \mathrm{T} \cdot \mathrm{V})$ was $50-120 \mathrm{~J} / \mathrm{mm}^{3}$ (mainly $60 \mathrm{~J} / \mathrm{mm}^{3}$ ). Cylindrical specimens built by laser sintering were cut from the support materials.

Cylindrical specimens with a diameter of $9 \mathrm{~mm}$ and a height of $50 \mathrm{~mm}$ were fabricated by laser sintering under the above conditions using EOSINT M 290 and EOSINT M 270 machines on support materials using the CP Ti G 2 powders. As shown in Figure 1, to investigate the effect of the building direction of laser sintering, the building direction was set to $0^{\circ}$ (hereafter, $0^{\circ}$ direction), $45^{\circ}\left(45^{\circ}\right.$ direction), and $90^{\circ}$ ( $90^{\circ}$ direction) for the base plate using the CP Ti G 2 powders [1]. CP Ti G 2 cylindrical specimens after laser sintering were heat-treated at $700{ }^{\circ} \mathrm{C}$ for $2 \mathrm{~h}$ followed by air cooling. This heat treatment (annealing) at $700^{\circ} \mathrm{C}\left( \pm 10^{\circ} \mathrm{C}\right)$ for $2 \mathrm{~h}$ is recommended by the FlexLine EOS material data. These conditions are also widely used for wrought Ti materials [14]. In the actual laser sintering of dental prostheses, a certain percentage of virgin powder is added. The number of repeated uses of the same powder of up to 10 times in this work was decided considering the effect of a small amount of residual powder. In the case of laser sintering from two to nine times, two cylindical specimens with a diameter of $9 \mathrm{~mm}$ and a height of $50 \mathrm{~mm}$ were laser-sintered in the $90^{\circ}$ direction in each sintering.

(a)

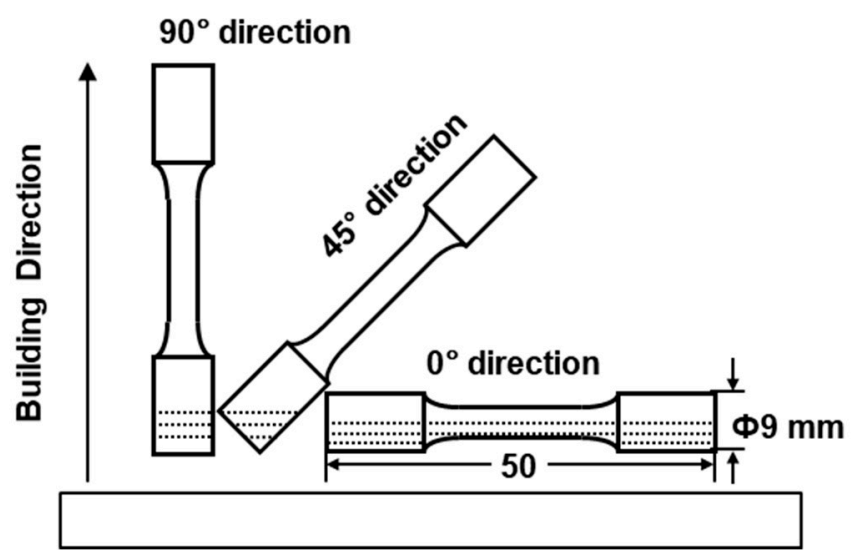

(b)

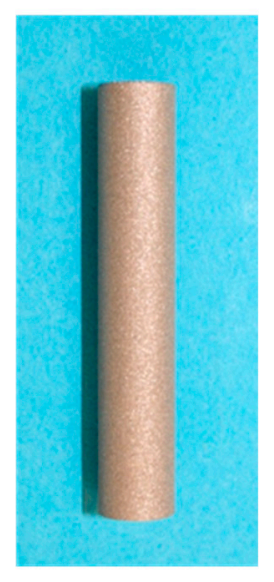

Figure 1. (a) Building directions of cylindrical specimens in laser sintering; (b) laser-sintered cylindrical specimens. 
For comparison, Ti-6Al-4V alloy was laser-sintered in the $90^{\circ}$ direction with the EOSINT M 290 machine (as-built Ti-6Al-4V alloy). To obtain two-phase grains with the $\alpha$ (hcp) and $\beta$ (bcc) phases, as seen in wrought Ti-6Al-4V alloy, the test specimens subjected to heat treatment were prepared from the laser-sintered Ti-6Al-4V alloy. The test specimens were heat-treated at 840, 860, 880, 900, $920,940,960$, and $980{ }^{\circ} \mathrm{C}$ for $2 \mathrm{~h}$ followed by air cooling [14]. The microstructure after annealing was observed by optical microscopy and scanning electron microscopy (SEM, Talos Thermo Fisher Scientific, Tokyo, Japan, Quanta 200FEG; acceleration voltage, $15 \mathrm{kV}$ ). The phases were also identified by $\mathrm{X}$-ray diffraction with $\mathrm{Cu} \mathrm{K} \alpha$ radiation (Rigaku, SmartLab, Tokyo, Japan; tube voltage, $45 \mathrm{kV}$; tube current, $200 \mathrm{~mA} ; 2^{\circ} / \mathrm{min}$; scan range $(2 \theta)$ of $\left.30^{\circ}-80^{\circ}\right)$.

An Ar gas pressure dental casting machine manufactured by Wada Precision Dental Laboratories (EZ Titan, Osaka, Japan) and an alumina phosphate investment mold (SUPER-VEST-D, Okazaki Minerals and Refining Co. Ltd., Osaka, Japan) were used to manufacture the cylindrical dental casts. CP Ti G 2 ingots of $40 \mathrm{~g}$ (30 mm diameter and $13 \mathrm{~mm}$ height; GC Corporation, Tokyo, Japan) used for conventional dental casts were employed as reference materials.

\subsubsection{Laser-Sintered Powders and Ti Material Rods}

Figure 2 shows (a) the particle size distribution and (b) SEM images of the CP Ti G 2 powders. Figure $2 \mathrm{a}$ also shows the $\mathrm{D}_{10}, \mathrm{D}_{50}$, and $\mathrm{D}_{90}$ particle sizes corresponding to $10 \%, 50 \%$, and $90 \%$ of the cumulative distribution, respectively. The particle size distributions of the powders were measured using an LA-750 particle size analyzer (Horiba, Ltd., Tokyo, Japan) in accordance with ISO 133320 [15]. EOS CP Ti G 2 particles were larger than TILOP CP Ti G 2 particles. The particle size distributions of the virgin TILOP powders and 10-times-sintered CP Ti powders showed the same tendency.
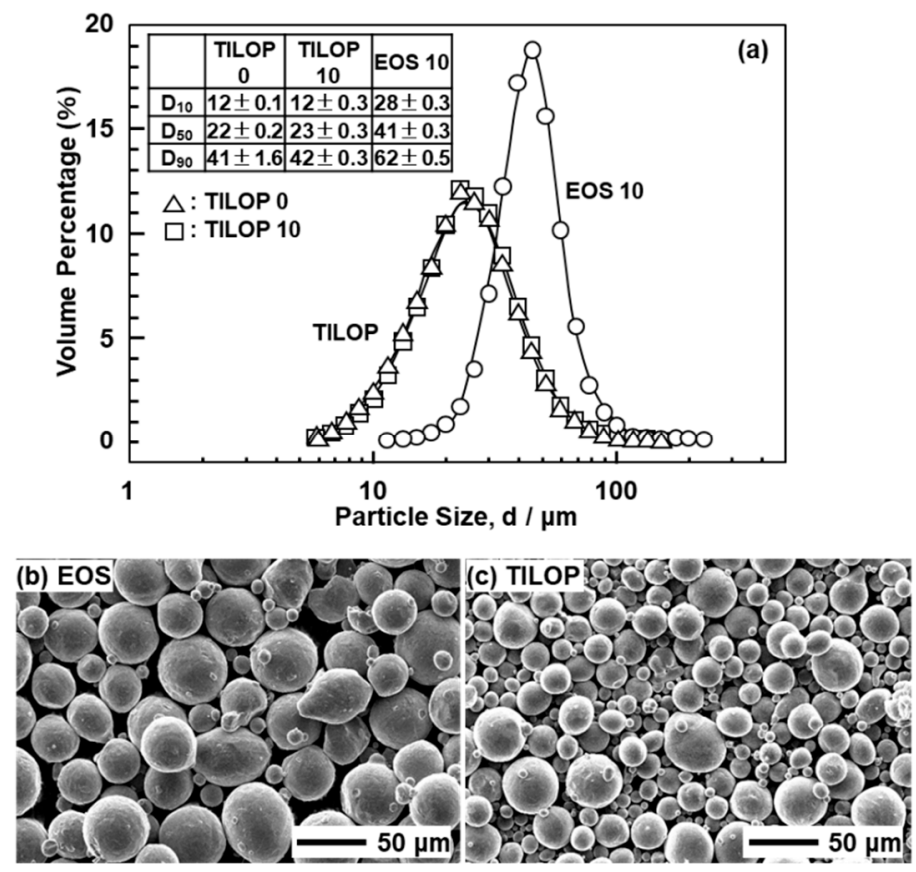

Figure 2. (a) Particle size distributions of 10-times-sintered EOS (EOS 10) and once-sintered (TILOP 0) and 10-times-sintered TILOP (TILOP 10) commercially pure (CP) Ti G 2 powders; SEM images of (b) 10-times-sintered EOS and (c) TILOP CP Ti G 2 powders.

The changes in the $\mathrm{D}_{10}, \mathrm{D}_{50}$, and $\mathrm{D}_{90}$ particle sizes of Ti-6Al-4V powders when the number of repetitions in AM is incresaed from once to five times are small according to the literature [6].

The chemical compositions of these powders and laser-sintered (as-built) CP Ti G 2 and Ti-6Al-4V alloy, and dental-cast CP Ti G 2 rods are shown in Table 1 . The H, N, O, Fe, C, Al, and V concentrations 
in the laser-sintered and dental-cast CP Ti G 2 rods and laser-sintered Ti-6Al-4V alloy rods were measured in accordance with Japanese Industrial Standard (JIS) H 1619 [16], JIS H 1612 [17], JIS H 1620 [18], JIS H 1614 [19], JIS H 1617 [20], JIS H 1622 [21], and JIS H 1624 [22], respectively. These chemical analyses were performed at Kobelco Research Institute, Inc. (Hyogo, Japan). Even when the number of repetitions in $\mathrm{AM}$ was increased from once to 10 times, the changes in metal concentrations (impurities) of the laser-sintered CP Ti G 2 rods were very small.

Table 1. Chemical compositions (mass \%) of CP Ti G 2 virgin powders, laser-sintered CP Ti G 2 and Ti-6Al-4V alloy, and dental-cast CP Ti G 2 rods.

\begin{tabular}{|c|c|c|c|c|c|c|c|c|}
\hline Alloy & Al & $\mathbf{V}$ & Fe & $\mathbf{O}$ & $\mathbf{N}$ & $\mathbf{H}$ & C & Ti \\
\hline EOS CP Ti G 2 virgin powder & & & 0.16 & 0.15 & 0.01 & 0.002 & 0.01 & Bal. \\
\hline 10-times-sintered powder & & & 0.17 & 0.15 & 0.008 & 0.0013 & 0.009 & Bal. \\
\hline 10-times-sintered CP Ti G 2 rod & & & 0.17 & 0.16 & 0.017 & 0.0014 & 0.008 & Bal. \\
\hline TILOP CP Ti G 2 virgin powder & & & 0.015 & 0.11 & $<0.005$ & 0.0037 & 0.005 & Bal. \\
\hline 10-times-sintered CP Ti powder & & & 0.015 & 0.12 & 0.006 & 0.0035 & 0.005 & Bal. \\
\hline Once-sintered CP Ti G 2 rod & & & 0.02 & 0.12 & 0.009 & 0.0032 & 0.002 & Bal. \\
\hline 10-times-sintered CP Ti G 2 rod & & & 0.02 & 0.12 & 0.007 & 0.0037 & 0.004 & Bal. \\
\hline Dental-cast CP Ti G 2 rod & & & 0.103 & 0.17 & 0.007 & 0.0022 & 0.007 & Bal. \\
\hline Ti-6Al-4V powder & 6.05 & 3.89 & 0.21 & 0.11 & 0.003 & 0.002 & 0.006 & Bal. \\
\hline Laser-sintered Ti-6Al-4V rod & 5.93 & 3.91 & 0.20 & 0.14 & 0.022 & 0.002 & 0.007 & Bal. \\
\hline
\end{tabular}

\subsection{Evaluation of Physical Properties}

The liquidus temperature of the laser-sintered CP Ti was measured by differential thermal analysis (DTA, TG-DTA 2200SA, Bruker Corp., Kanagawa, Japan) [14]. Test specimens of $3 \mathrm{~mm}$ diameter and $1.5 \mathrm{~mm}$ height were cut from the laser-sintered CP Ti G 2. Heat flows in DTA were measured at a heating rate of $10{ }^{\circ} \mathrm{C} / \mathrm{min}$ in Ar at a flow rate of $200 \mathrm{~mL} / \mathrm{min}$. The densities ( $\rho$ ) of powder and laser-sintered CP Ti G 2 were measured using an Ultrapycnometer 1000 M-UPYC (Quantachrome Instruments, Kanagawa, Japan) by gas pycnometry in accordance with JIS R1620 [23]. The Vickers hardness ( $\mathrm{Hv}$ ) of each laser-sintered CP Ti G 2 rod at room temperature was measured with a Vickers hardness tester (FV-310, Future-Tech Corp., Kanagawa, Japan) at three to five points at a load of $10 \mathrm{~kg}$.

\subsection{Microstructural Observation}

The CP Ti G 2 annealed after laser sintering and laser-sintered (as-built) Ti-6Al-4V alloy were embedded in resin and polished to a mirrorlike finish with 200-4200 grit waterproof emery paper and an oxide polishing (OP-S) suspension. Then, each specimen was etched with nitric acid solution containing $3 \mathrm{vol} \%$ hydrogen fluoride. The microstructures of the CP Ti G 2 annealed at $700{ }^{\circ} \mathrm{C}$ for $2 \mathrm{~h}$ after laser sintering and laser-sintered (as-built) Ti-6Al-4V alloy were analyzed by optical microscopy (Nikon ECLIPSE LV150, Tokyo, Japan) and transmission electron spectroscopy (TEM, Hitachi HF-2000, Tokyo, Japan; acceleration voltage, $200 \mathrm{kV}$ ) with energy dispersive $X$-ray spectroscopy (EDS 2008 ver. 1.2 RevE, IXRF Systems, Tokyo, Japan). After etching, the surfaces of the annealed CP Ti G 2 and as-built Ti-6Al-4V alloy were observed by optical microscopy at magnifications of 50 $\times$ and $400 \times$. TEM was performed using disc-shaped specimens of $3 \mathrm{~mm}$ diameter, which were prepared by electrolytic polishing with $5 \mathrm{vol} \%$ perchloric acid $+60 \mathrm{vol} \%$ methanol $+35 \mathrm{vol} \%$ butanol solution under conditions of $30 \mathrm{~V}$ and $75 \mathrm{~mA}$ at $-30^{\circ} \mathrm{C}$. After electrolytic polishing, the transverse cross-sectional structure was observed by TEM at magnifications of $15,000 \times$ and $60,000 \times$. The fracture surfaces after the tensile and fatigue tests were observed by SEM.

\subsection{Static Immersion Test}

The specimens $(\mathrm{n}=2)$, each with dimensions of $15 \mathrm{~mm} \times 32 \mathrm{~mm} \times 1 \mathrm{~mm}$, were laser-sintered (as-built) and dental-cast CP Ti G 2 plates. Immersion tests were conducted at $37 \pm 1{ }^{\circ} \mathrm{C}$ in an incubator using $0.1 \mathrm{~mol} / \mathrm{L}$ lactic acid $+0.1 \mathrm{~mol} / \mathrm{L} \mathrm{NaCl}$ solution $(\mathrm{pH}=2.3)$ [1] in accordance with ISO 10271 [24] and JIS T 6115 [25]. The concentration of Ti released into the solution over $7 \mathrm{~d}$ was determined $(\mathrm{ng} / \mathrm{mL})$ by inductively coupled plasma mass spectrometry (ICP-MS, NexION 300D, PerkinElmer, Kanagawa, 
Japan; isotopic mass number of Ti, 48). An internal standard solution of $Y$ (isotopic mass number, 89) was used for correction of the Ti concentration. The mean amount of Ti released $\left(\mu \mathrm{g} / \mathrm{cm}^{2} /\right.$ week) and the standard deviation were calculated for two specimens.

\subsection{Room-Temperature Tensile Tests}

Uniform rod specimens (rod diameter, $3 \mathrm{~mm}$; gauge length, $15 \mathrm{~mm}$ ) were cut from cylindrical specimens with a diameter of $9 \mathrm{~mm}$ and a height of $50 \mathrm{~mm}[1,26,27]$. Tensile test specimens for dental-cast CP Ti G 2 were also cut from cylindrical specimens without defects as determined by $X$-ray inspection. The tensile test specimens were pulled with an Instron 5567 testing machine at a crosshead speed of $0.5 \%$ of the gauge length $(\mathrm{GL}) / \mathrm{min}$ until the proof stress reached $0.2 \%$. The crosshead speed was then changed to $3 \mathrm{~mm} / \mathrm{min}$ and maintained at this speed until the specimen fractured. The $0.2 \%$ proof stress $\left(\sigma_{0.2 \% \mathrm{PS}}\right), \sigma_{\mathrm{UTS}}$, total elongation (TE) at breaking, reduction in area (RA), and elastic modulus (E) were measured in tensile tests. The mean and standard deviation were calculated from the results of at least four specimens.

\subsection{Fatigue Tests}

Miniature hourglass-shaped rod specimens ( $3 \mathrm{~mm}$ minimum diameter and $50 \mathrm{~mm}$ total length) cut from cylindrical specimens were used for fatigue tests [1,28]. The fatigue tests were carried out with a sine wave at a stress ratio $\mathrm{R}$ (minimum cyclic stress $\left(\sigma_{\min }\right) /\left(\right.$ maximum cyclic stress $\left(\sigma_{\max }\right)$ ) of 0.1 and a frequency of $15 \mathrm{~Hz}$ in air. To obtain profiles of the relationship between $\sigma_{\max }$ and the number of cycles to failure $\mathrm{N}$ (S-N curves), the specimens were subjected to cycling at various constant maximum cyclic loads up to $\mathrm{N}=10^{7}$ cycles, at which the specimens remained intact. The fatigue strength at $10^{7}$ cycles (fatigue limit, $\sigma_{\mathrm{FS}}$ ) was measured from the $\mathrm{S}-\mathrm{N}$ curves.

\section{Results and Discussion}

\subsection{Chemical Compositions and Physical Properties}

Table 1 shows the chemical compositions of laser-sintered (as-built) CP Ti G 2 and Ti-6Al-4V alloy rods with virgin powders (hereafter, once-sintered CP Ti G 2 rod), and the compositions after laser sintering 10 times (10-times-sintered CP Ti G 2 rod) with the same CP Ti G 2 powders without the virgin powder added. The changes in the chemical composition of the 10-times-sintered CP Ti G 2 rod were negligible. The results shown in Table 1 were in good agreement with the FlexLine EOS material data sheet and the Ti-6Al-4V material mill test certificate.

Figure 3 shows the oxygen $(\mathrm{O})$ concentration in laser-sintered EOS CP Ti G 2 rods, laser-sintered TILOP CP Ti G 2 rods, and TILOP CP Ti G 2 powders as a function of the number of times of repeated laser sintering. The bars in Figure 3 indicate the standard deviation. In Figure 3, the results for the Ti-6Al-4V alloy were taken from the literature [6]. The increase in the $\mathrm{O}$ concentration of the laser-sintered CP Ti G 2 rods was found to be negligible. The $\mathrm{O}$ concentration in the laser-sintered Ti-6Al-4V alloy slightly increased from $0.11 \%$ in the virgin powder to $0.14 \%$ in the once-sintered alloy. On the other hand, in a previous report, the $\mathrm{O}$ concentration of the laser-sintered Ti-6Al-4V alloys was increased to up to $0.21 \%$ by laser sintering [6]. In particular, almost no increase in O concentration was observed after sintering 10 times. Thus, it was found that CP Ti powder can be recycled up to 10 times in the laser sintering of $\mathrm{CP}$ Ti. These tendencies were similar to those obtained with laser-sintered Co-Cr-Mo alloys [1]. 


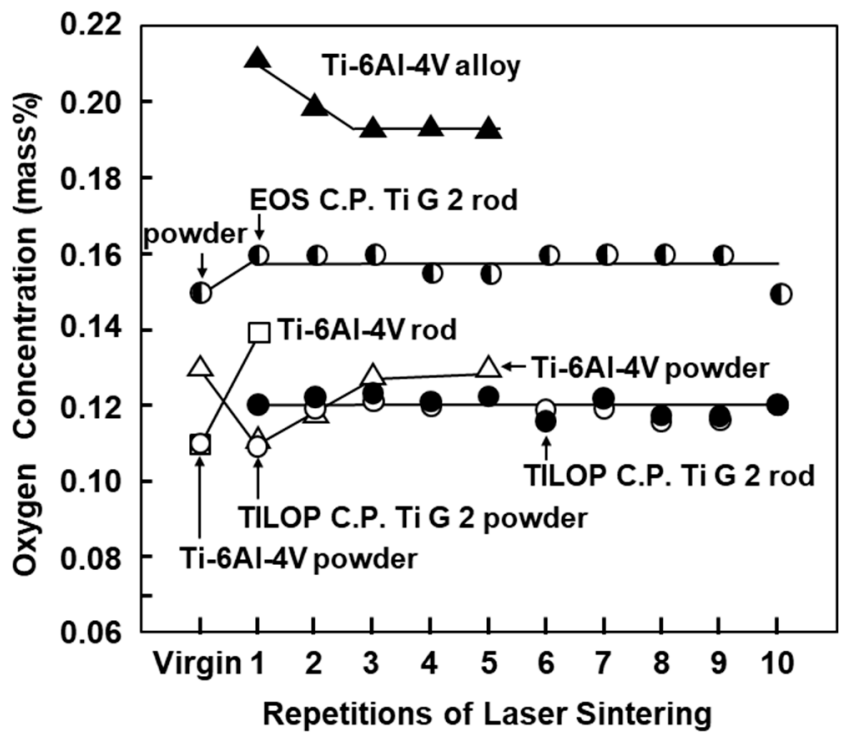

Figure 3. Effect of repeated laser sintering on oxygen concentration in Ti powders and laser-sintered Ti materials.

The densities of EOS virgin powder and once-sintered and 10-times-sintered (as-built) CP Ti G 2 rods were $4.49,4.50$, and $4.50 \mathrm{~g} / \mathrm{cm}^{3}$, respectively. The densities of TILOP virgin CP Ti G 2 powder and 10-times-sintered CP Ti G 2 rod were the same. These values are also consistent with the value $\left(4.50 \mathrm{~g} / \mathrm{cm}^{3}\right)$ shown in the FlexLine EOS material data sheet. Moreover, these densities of laser-sintered CP Ti G 2 were close to that $\left(4.5 \mathrm{~g} / \mathrm{cm}^{3}\right)$ of the wrought CP Ti G 2 ([29], p. 126). These values are much lower than the densities $\left(8.4-8.8 \mathrm{~g} / \mathrm{cm}^{3}\right)$ of the laser-sintered Co-Cr-Mo alloys [1].

The liquidus temperatures of once-sintered and 10-times-sintered TILOP CP Ti G 2 rods measured by DTA were 1659 and $1662{ }^{\circ} \mathrm{C}$, respectively. These liquidus temperatures were close to those $\left(1663 \pm 1^{\circ} \mathrm{C}\right)$ of wrought $\mathrm{CP}$ Ti G 2 reported in the literature [14]. The liquidus temperature of $\mathrm{CP} \mathrm{Ti} \mathrm{G}$ 2 was much higher than those $\left(1458-1463^{\circ} \mathrm{C}\right)$ of laser-sintered $\mathrm{Co}-\mathrm{Cr}-\mathrm{Mo}$ alloys [1].

The amounts of Ti ions released from the once-sintered TILOP and dental-cast CP Ti G 2 plates were $1.90 \pm 0.10$ and $1.10 \pm 0.05 \mu \mathrm{g} / \mathrm{cm}^{2} /$ week, respectively. These values were close to the amount $\left(1.2 \mu \mathrm{g} / \mathrm{cm}^{2} /\right.$ week $)$ of Ti ions released from wrought Ti-6Al-4V alloy at $\mathrm{pH}=2.3$ reported in the literature [30].

The Hv values $(n=5)$ of transverse sections of the 10-times-sintered $90^{\circ} \mathrm{EOS}$ and once-sintered $90^{\circ}$ TILOP CP Ti G 2 rods, and dental-cast CP Ti G 2 were $187 \pm 4,207 \pm 6$, and $169 \pm 6$, respectively. These values were close to the $\mathrm{Hv}$ (approximately 200-210) of dental-cast CP Ti G 2 in the literature [8,12].

\subsection{Microstructure of Laser-Sintered Ti Materials}

Figure 4 shows optical microscopy images of transverse $(\mathrm{T})$ and longitudinal (L) sections of annealed CP Ti G 2 rods after laser sintering $\left(90^{\circ}\right.$ and $0^{\circ}$ directions). Similar microstructures were observed in the transverse and longitudinal sections of $0^{\circ}$ - and $45^{\circ}$-direction-built specimens. As clearly shown in Figure 4e, the structure of CP Ti G 2 annealed at $700{ }^{\circ} \mathrm{C}$ for $2 \mathrm{~h}$ after laser sintering was similar to that of CP Ti G 2 annealed under the same conditions after hot forging. On the other hand, as shown in Figure 4f, the center part of the dental-cast CP Ti G 2 rod had an $\alpha$ phase with an hcp crystal structure [8]. Figure 5 shows TEM images of transverse sections of annealed $\mathrm{CP}$ Ti G 2 after $90^{\circ}$-direction-built laser sintering. The bcc structure (lattice parameters $\mathrm{a}=\mathrm{b}=\mathrm{c}$ $=0.331 \mathrm{~nm})$ precipitated in the grain boundaries of the hcp structure $(\mathrm{a}=\mathrm{b}=0.295, \mathrm{c}=0.468 \mathrm{~nm})$ matrix. The values of these lattice parameters were consistent with those in a handbook of Ti material properties ([29], p. 125). 

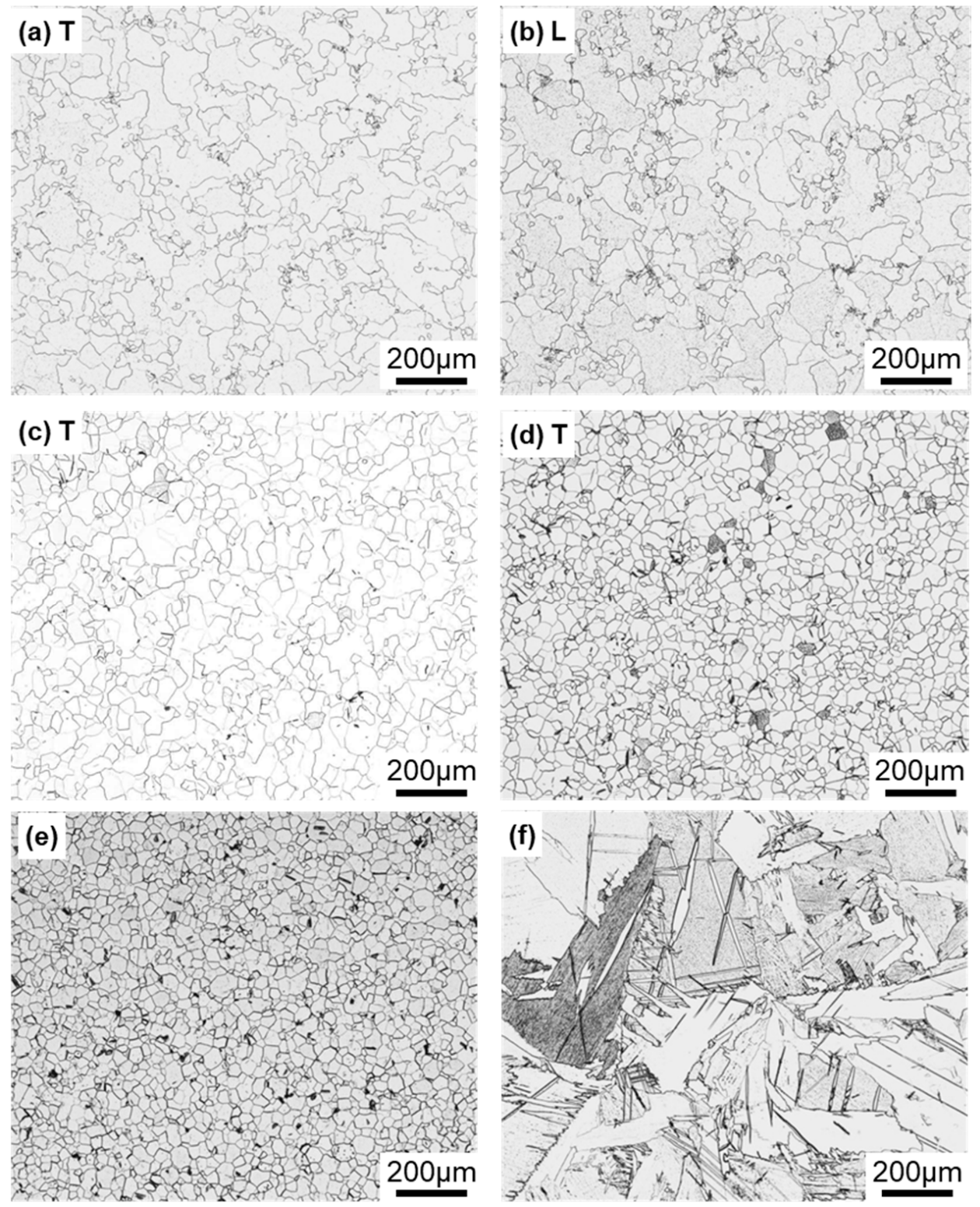

Figure 4. Optical microscopy images of $(\mathbf{a}, \mathbf{b})$ 10-times-laser-sintered EOS CP Ti G 2 and $(\mathbf{c}, \mathbf{d})$ once-sintered TILOP CP Ti G 2 built in $(\mathbf{a}-\mathbf{c}) 90^{\circ}$ and (d) $0^{\circ}$ directions; $(\mathbf{a}, \mathbf{c}, \mathbf{d})$ transverse $(\mathrm{T})$ sections to the building direction and (b) longitudinal ( $\mathrm{L}$ ) section perpendicular to the building direction; (e,f) optical microscopy images of wrought and dental-cast (center part) CP Ti G 2 rods, respectively.

For comparison, optical microscopy and SEM images of laser-sintered Ti-6Al-4V alloy are shown in Figure $6 \mathrm{a}-\mathrm{d}$. The laser-sintered Ti-6Al-4V alloy had an acicular structure. Figure 6e,f show TEM images of transverse sections of $90^{\circ}$-direction-built laser-sintered Ti-6Al-4V alloy. TEM images of the laser-sintered (as-built) Ti-6Al-4V alloy show that it consisted of a fine martensitic $\left(\alpha^{\prime}\right)$ needle-like microstructure (hcp, a $=b=0.295, c=0.468 \mathrm{~nm}$ ) formed owing to rapid solidification [31-38]. 

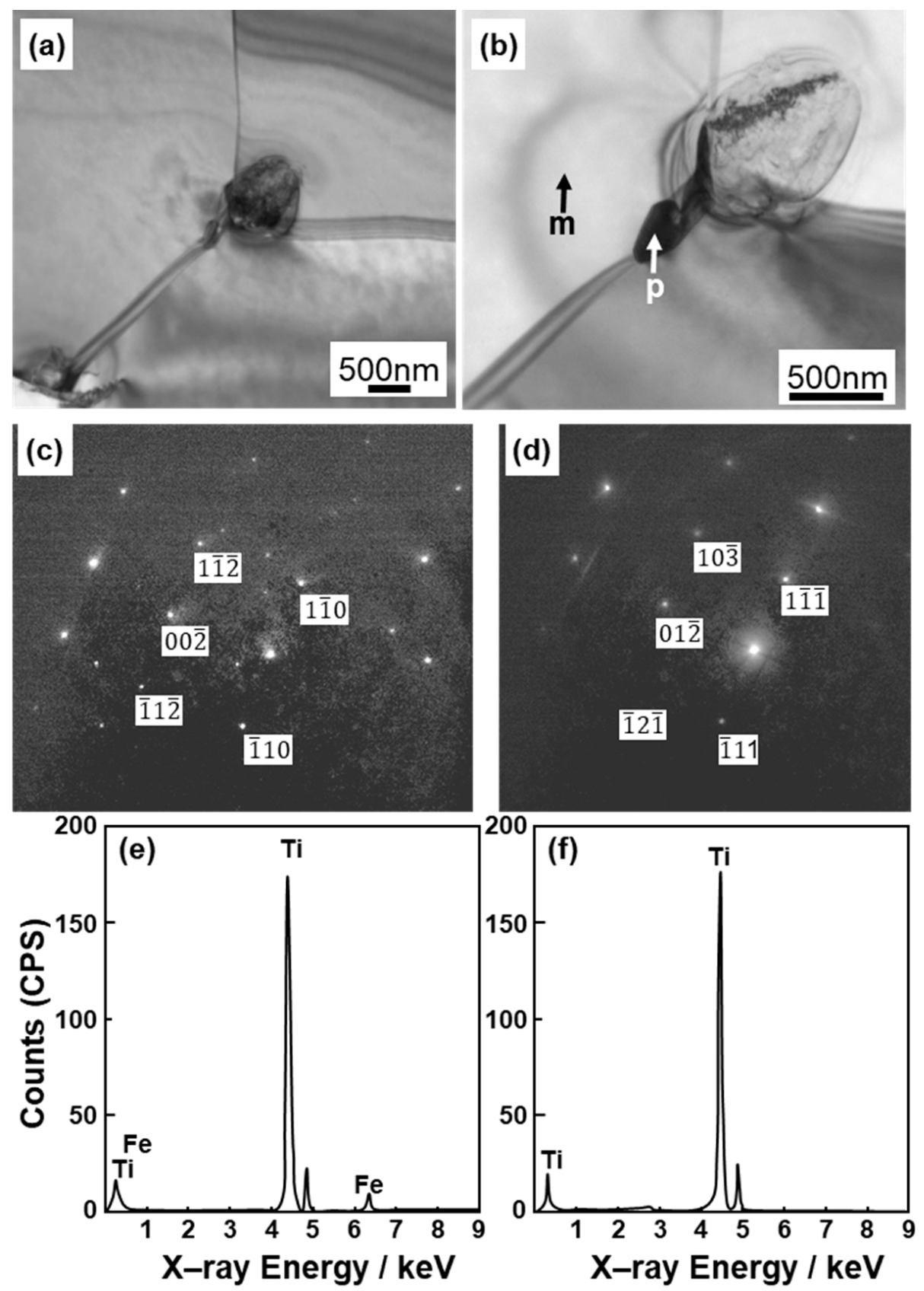

Figure 5. TEM images of transverse sections of $(\mathbf{a}, \mathbf{b})$ once-sintered TILOP CP Ti G 2 built in $90^{\circ}$ direction; (c,d) electron beam diffraction patterns obtained at the location indicated by $\mathrm{p}$ (precipitation) and $\mathrm{m}$ (matrix) in (b), respectively; (e,f) EDS patterns of precipitate indicated by $\mathrm{p}$ and $\mathrm{m}$ in (b).

Figure 7 shows optical microscopy and SEM images of the Ti-6Al-4V alloy annealed at 840, 900, and $920^{\circ} \mathrm{C}$ for $2 \mathrm{~h}$ after laser sintering of the alloy built in the $90^{\circ}$ direction. In X-ray diffraction, most of the $\alpha$-phase (hcp) contained a very small amount of the $\beta$-phase (bcc). Similar microstructures were observed in the optical images of specimens annealed at $860,880,940,960$, and $980{ }^{\circ} \mathrm{C}$. The $\alpha$-phase tended to become coarse with increasing annealing temperature. The annealed alloy retained its needle-like structure and did not change to a two-phase structure of $\alpha(\mathrm{hcp})-\beta$ (bcc), in contrast to the wrought Ti-6Al-4 V alloy $[13,39]$. Hv $(n=5)$ of each transverse section in the heat treatment range decreased from 342 to 316 and tended to decrease slowly with increasing annealing temperature. 

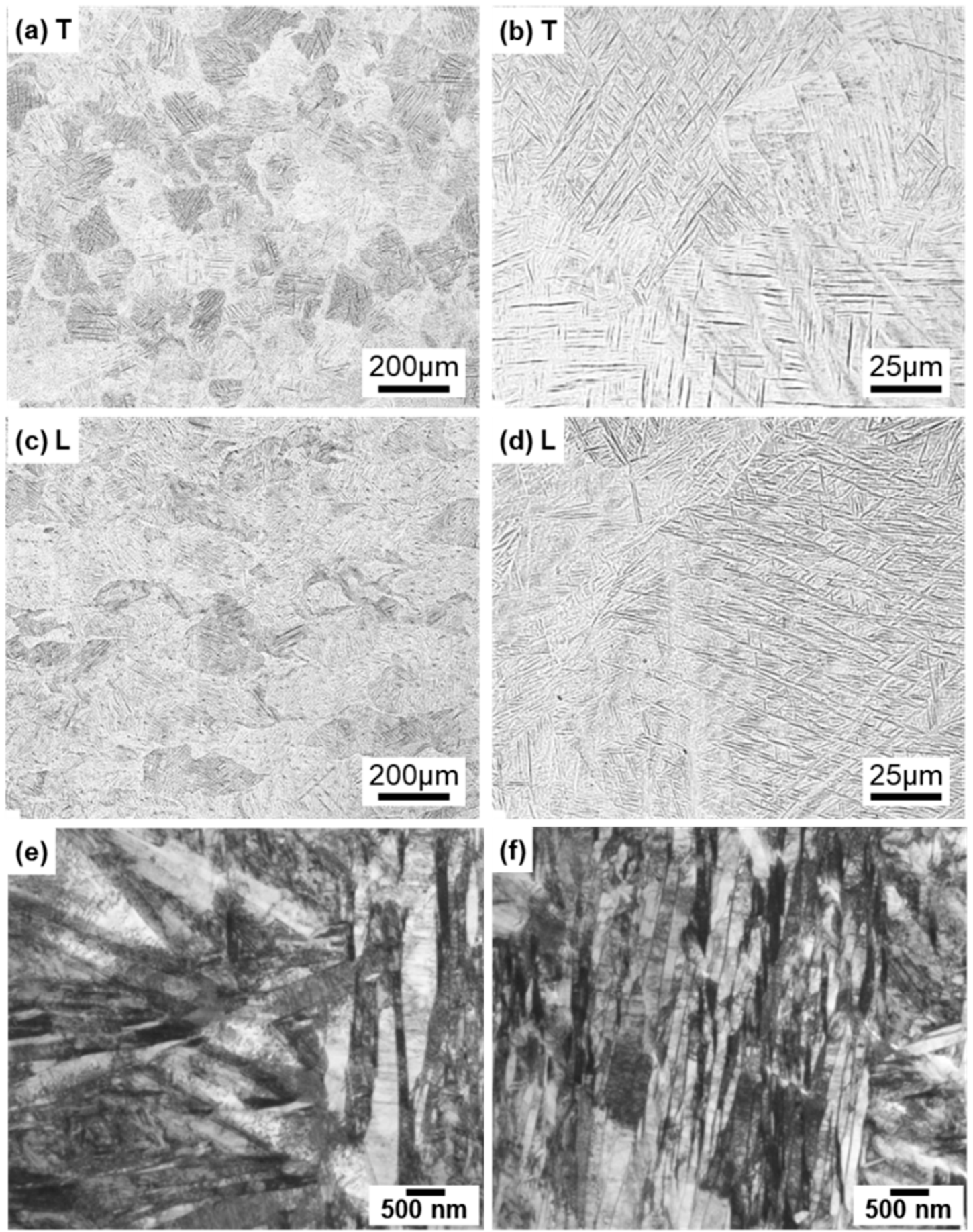

Figure 6. Optical microscopy images of once-sintered Ti-6Al-4V alloys built in $90^{\circ}$ direction; $(\mathbf{a}, \mathbf{b})$ transverse $(\mathrm{T})$ sections to the building direction and $(\mathbf{c}, \mathbf{d})$ longitudinal $(\mathrm{L})$ sections perpendicular to the building direction; $(\mathbf{e}, \mathbf{f})$ TEM images of transverse section of once-sintered Ti-6Al-4V alloys built in $90^{\circ}$ direction. 

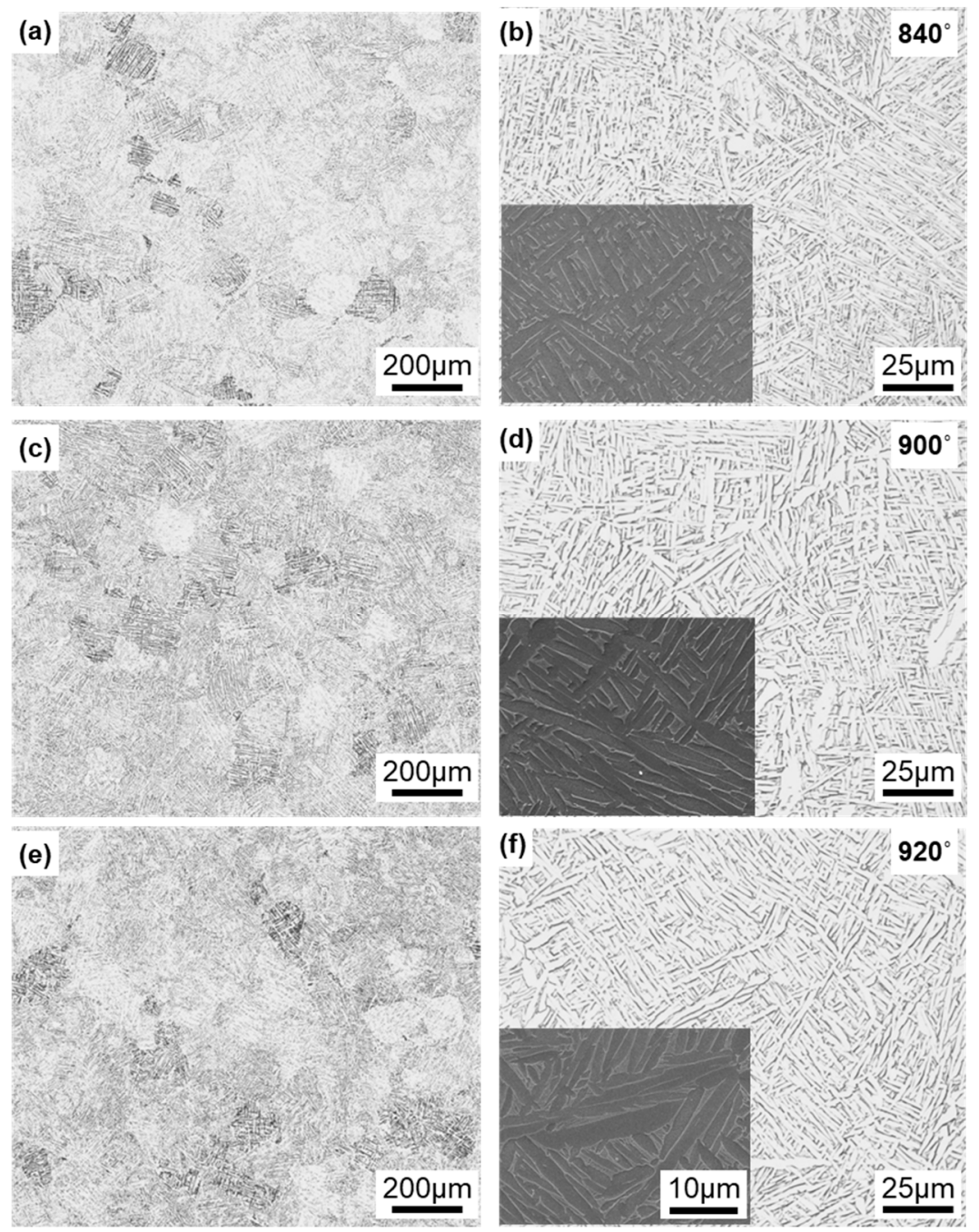

Figure 7. Optical microscopy and SEM images of Ti-6Al-4V alloy annealed at (a,b) 840, (c,d) 900, and $(\mathbf{e}, \mathbf{f}) 920^{\circ} \mathrm{C}$ for $2 \mathrm{~h}$ after laser sintering.

\subsection{Mechanical Properties of Laser-Sintered Ti Materials}

Figure 8 shows the mechanical properties $\left(\sigma_{0.2 \% \mathrm{PS}}, \sigma_{\mathrm{UTS}}, \mathrm{TE}\right.$, and RA) of laser-sintered EOS CP Ti $\mathrm{G} 2$ rods as a function of number of the repetitions of laser sintering. Hardly any effect of the number of repetitions on $\sigma_{0.2 \% \mathrm{PS}}, \sigma_{\mathrm{UTS}}, \mathrm{TE}$, and RA was observed up to 10 repetitions.

Table 2 summarizes the tensile properties (mean \pm standard deviation) of the CP Ti G 2 annealed after laser sintering, the laser-sintered (as-built) Ti-6Al-4V alloy, and the dental-cast CP Ti G 2. The tensile properties of annealed (wrought) CP Ti G 2 and Ti-6Al-4V alloy after hot forging shown in Table 2 are taken from the literature [39]. The strengths of the 10-times-sintered CP Ti were similar to those of the once-sintered CP Ti. In particular, it was found that the tensile strengths of the annealed CP Ti G 2 after laser sintering were close to those of the annealed (wrought) CP Ti G 2 after hot forging. Table 2 also shows the tensile properties of wrought CP Ti G 2 specified in ISO 5832-3 [4]. The mechanical properties of the CP Ti G 2 annealed after laser sintering obtained in this study satisfied these standard values. However, $\sigma_{0.2} \% \mathrm{PS} \geq 500 \mathrm{MPa}$ specified in the dental standard ISO 22674 was not satisfied [26]. These characteristics of the laser-sintered CP Ti G 4 materials $(\mathrm{O} \leq 0.4 \%)$ with CP Ti G 4 powder were expected because the same annealed microstructure as the wrought CP Ti G 4 material was obtained. The elastic moduli of the laser-sintered and dental-cast CP Ti G 2 rods were $113 \pm 2$ and $115 \pm 4 \mathrm{GPa}$, respectively. These values were lower than the value in ISO 22674 ( $\geq 150 \mathrm{GPa}$ ) [26]. 


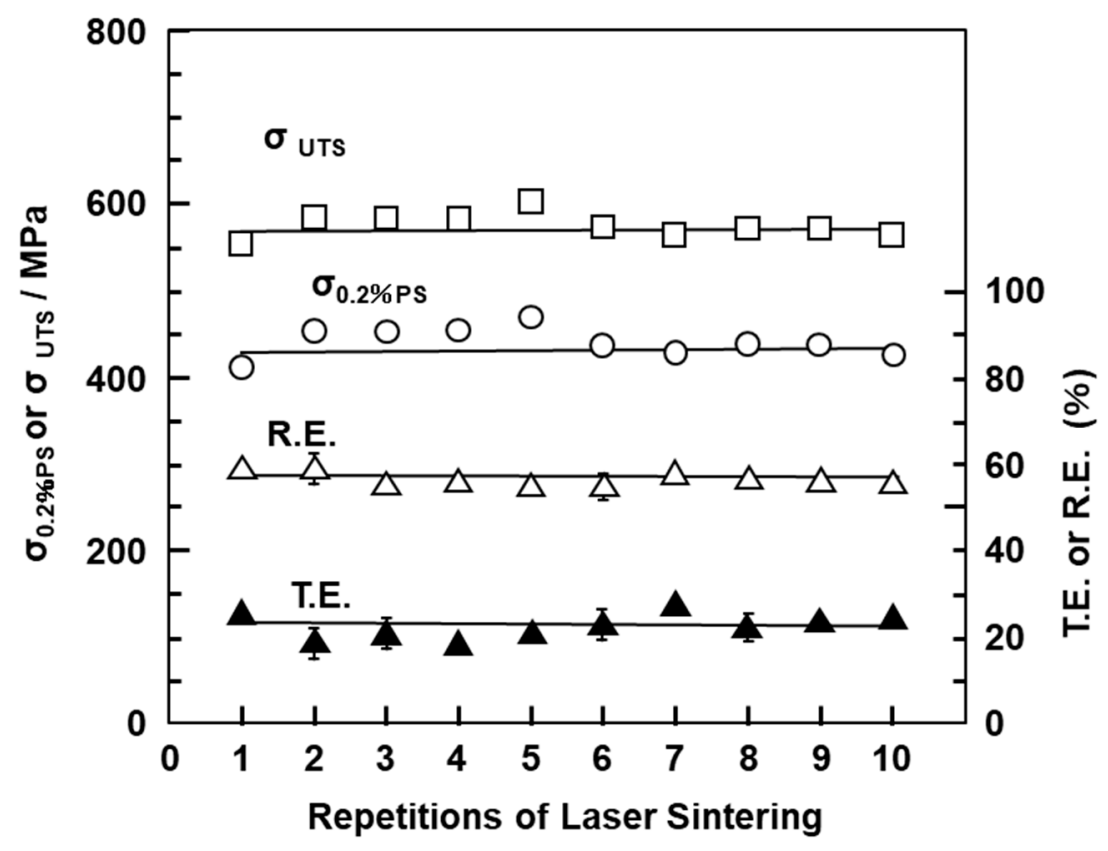

Figure 8. Effects of repeated laser sintering on mechanical properties $\left(\sigma_{0.2} \%\right.$ PS, $\sigma_{\text {UTS }}, \mathrm{TE}$, and RA $)$ of laser-sintered EOS CP Ti G 2 rods.

Table 2. Tensile properties $\left(\sigma_{0.2 \% \mathrm{PS}}, \sigma_{\mathrm{UTS}}, \mathrm{TE}\right.$, and RA), fatigue strength $\left(\sigma_{\mathrm{FS}}\right)$, and fatigue ratio $\left(\sigma_{\mathrm{FS}} / \sigma_{\mathrm{UTS}}\right)$ of CP Ti G 2 and Ti-6Al-4V alloys manufactured under various conditions.

\begin{tabular}{|c|c|c|c|c|c|c|}
\hline Specimen & $\begin{array}{c}\sigma_{0.2 \% \mathrm{PS}} \\
/ \mathrm{MPa}\end{array}$ & $\begin{array}{c}\sigma_{\text {UTS }} \\
/ \mathrm{MPa}\end{array}$ & $\begin{array}{l}\text { TE } \\
(\%)\end{array}$ & $\begin{array}{l}\text { RA } \\
(\%)\end{array}$ & $\begin{array}{c}\sigma_{\mathrm{FS}} \\
/ \mathrm{MPa}\end{array}$ & $\begin{array}{c}\sigma_{\mathrm{FS}} \\
/ \sigma_{\mathrm{UTS}}\end{array}$ \\
\hline \multicolumn{7}{|l|}{ EOS CP Ti G 2} \\
\hline Once-sintered $90^{\circ}$ & $412 \pm 2$ & $553 \pm 3$ & $26 \pm 1$ & $59 \pm 1$ & 320 & 0.58 \\
\hline 10 -times-sintered $0^{\circ}$ & $437 \pm 2$ & $576 \pm 1$ & $28 \pm 2$ & $55 \pm 1$ & 365 & 0.63 \\
\hline $\begin{array}{l}\text { 10-times-sintered } 90^{\circ} \\
\text { TILOP CP Ti G } 2\end{array}$ & $426 \pm 1$ & $565 \pm 1$ & $25 \pm 1$ & $56 \pm 1$ & 320 & 0.57 \\
\hline Once-sintered $90^{\circ}$ & $445 \pm 2$ & $578 \pm 3$ & $27 \pm 5$ & $36 \pm 10$ & 330 & 0.57 \\
\hline Once-sintered $0^{\circ}$ & $432 \pm 6$ & $576 \pm 5$ & $26 \pm 3$ & $50 \pm 1$ & 380 & 0.66 \\
\hline Once-sintered $45^{\circ}$ & $419 \pm 4$ & $557 \pm 3$ & $22 \pm 5$ & $47 \pm 6$ & 290 & 0.52 \\
\hline 10-times-sintered $90^{\circ}$ & $371 \pm 4$ & $481 \pm 6$ & $22 \pm 8$ & $41 \pm 14$ & 340 & 0.71 \\
\hline Dental-cast CP Ti G 2 & $351 \pm 2.2$ & $466 \pm 3$ & $30 \pm 6$ & $68 \pm 5$ & 290 & 0.62 \\
\hline Wrought CP Ti G 2 & $276 \pm 6$ & $410 \pm 4$ & $40 \pm 2$ & $60 \pm 6$ & 280 & 0.68 \\
\hline Laser-sintered Ti-6Al-4V & $1171 \pm 3$ & $1305 \pm 2$ & $13 \pm 1$ & $31 \pm 3$ & 600 & 0.46 \\
\hline Wrought Ti-6Al-4V & $849 \pm 1$ & $934 \pm 1$ & $16 \pm 1$ & $42 \pm 3$ & 680 & 0.73 \\
\hline ISO 5832-4 & $\geq 275$ & $\geq 345$ & $\geq 20$ & & & \\
\hline
\end{tabular}

Considering the dental application of high-strength $\mathrm{Ti}$ alloy, the mechanical properties of laser-sintered Ti-6Al-4V alloy are compared in Table 2. The tensile properties of the laser-sintered Ti-6Al-4V alloy were higher than those of the dental-cast Ti alloys $[8,10]$. The mechanical strength of laser-sintered Ti-6Al-4V alloy was also higher than that of wrought Ti-6Al-4V alloy [39]. On the other hand, the ductility of laser-sintered Ti-6Al-4V alloy was close to that of wrought Ti-6Al-4V alloy. The tensile properties of laser-sintered Ti-6Al-4V alloy fully satisfied the tensile properties $\left(\sigma_{0.2} \% \mathrm{PS} \geq 780, \sigma_{\mathrm{UTS}} \geq 860 \mathrm{MPa}, \mathrm{TE} \geq 10 \%\right)$ specified in ISO 5832-3 [5]. The tensile properties obtained in this study were also similar to those reported in the literature [32-37]. The tensile strength of Ti-6Al-4V alloy annealed after laser sintering tended to be lower than that of the as-built Ti-6Al-4V alloy [36,38]. To increase the ductility of alloys, it is effective to improve the morphology of the needle-like microstructure by heat treatment [33-35].

The Ti-6Al-4V alloy has much lower fracture toughness (Charpy V-notch impact toughness) than CP Ti G 2 ([29], p. 238). The fracture toughness of laser-sintered Ti-6Al-4V alloy should be evaluated in the future. 
Figure 9 shows SEM images of the fracture surfaces of laser-sintered CP Ti G 2 after the tensile test. Magnified images of the rectangular areas in Figure 9a,b are shown in Figure 9b,c, respectively. Dimples were observed on the fracture surfaces, as shown in Figure 9c. Similar fracture surfaces were observed on all the other laser-sintered CP Ti G 2 specimens.
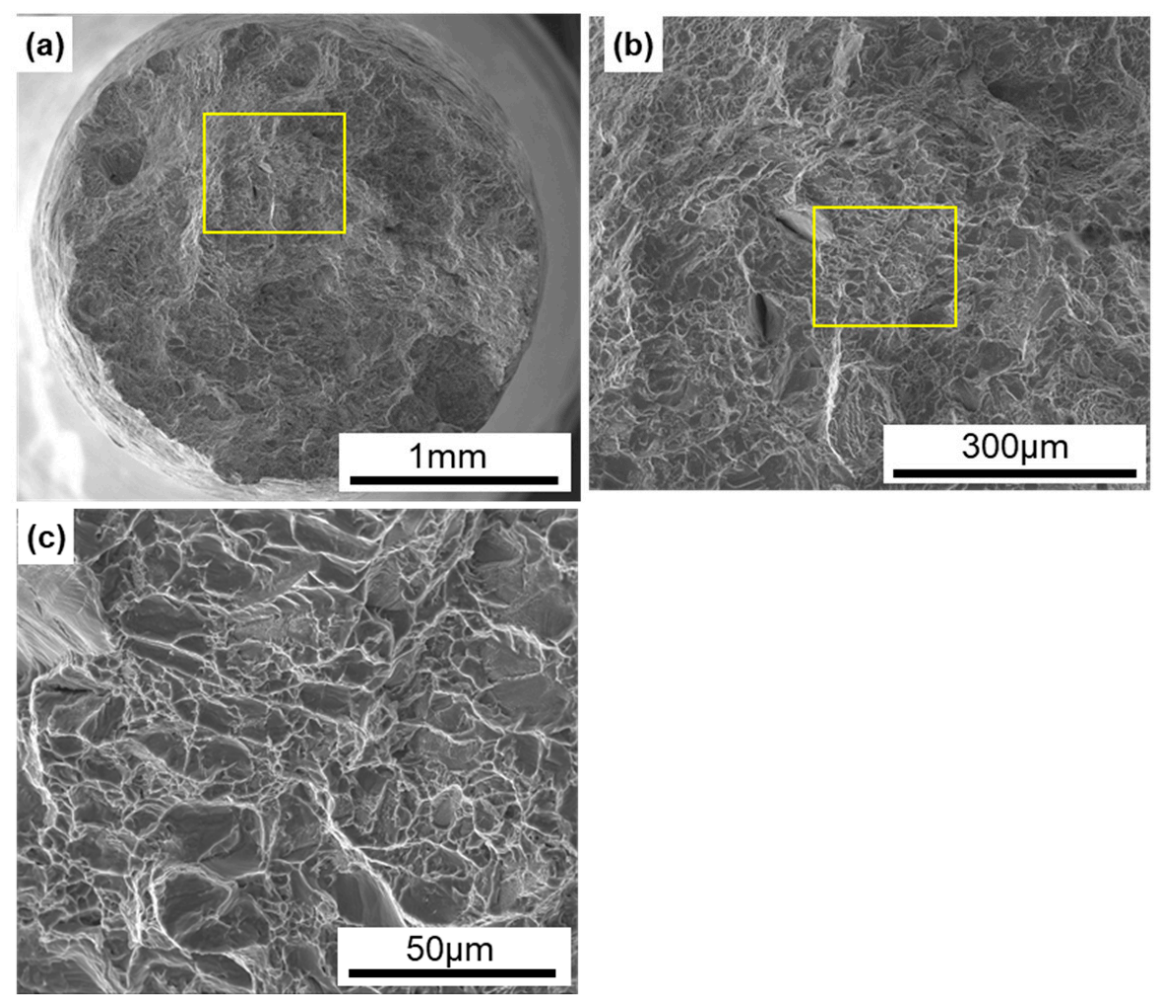

Figure 9. SEM images of fracture surfaces of the tensile-tested TILOP CP Ti G 2 (10-times-sintered); (b) magnification of rectangular area in (a), and (c) magnification of rectangular area in (b).

\subsection{Fatigue Strengths of Laser-Sintered Ti Materials}

Figure 10a,b shows S-N curves of annealed CP Ti G 2 rods ((a) EOS and (b) TIROP powders) after laser sintering and dental-cast CP T G 2 (shown in Figure 10a). Figure 10b also shows S-N curves of CP Ti G 2 annealed after hot forging taken from the literature for comparison [39]. The fatigue strengths of the $90^{\circ}-, 45^{\circ}-$, and $0^{\circ}$-direction-built CP Ti G 2 rods were $\sim 330, \sim 290$, and $\sim 380 \mathrm{MPa}$, respectively. The effects of the laser sintering direction on $\sigma_{\mathrm{FS}}$ of CP Ti G 2 were considered to be small because the anisotropy factor of the fatigue strength was 0.87 ((fatigue strength in $90^{\circ}$ direction)/(fatigue strength in $0^{\circ}$ direction)). This value was similar to those obtained for the laser-sintered Co-Cr-Mo alloy (0.83-1.0) [1] and the anisotropy of $\sigma_{0.2 \% \mathrm{PS}}$ caused by forging of Ti-15Zr-4Nb-4Ta alloys $(0.83-0.94)$ [40]. Thus, it was considered that the effect of the laser sintering direction is negligible for CP Ti G 2. The fatigue strength of the $90^{\circ}$-direction-built 10-times-sintered CP Ti G 2 was $\sim 340 \mathrm{MPa}$.

Figure 11 shows S-N curves of laser-sintered (as-built) Ti-6Al-4V alloy and wrought Ti-6Al-4V alloy annealed at $700{ }^{\circ} \mathrm{C}$ for $2 \mathrm{~h}$ after hot forging; the curve for wrought Ti-6Al-4V alloy is taken from the literature for comparison [39]. The fatigue strength of the $90^{\circ}$-direction-built Ti-6Al-4V alloy was $\sim 600 \mathrm{MPa}$, which is close to that of wrought Ti-6Al-4V alloy. The improvements in the fatigue strength and durability of dental prostheses (such as partial dentures and clasps) are effective in improving the needle-like structure and reducing the thermal stress caused by laser sintering. We would like to investigate in detail the other orthopedic applications of laser-sintered Ti-6Al-4V alloy in future studies. 

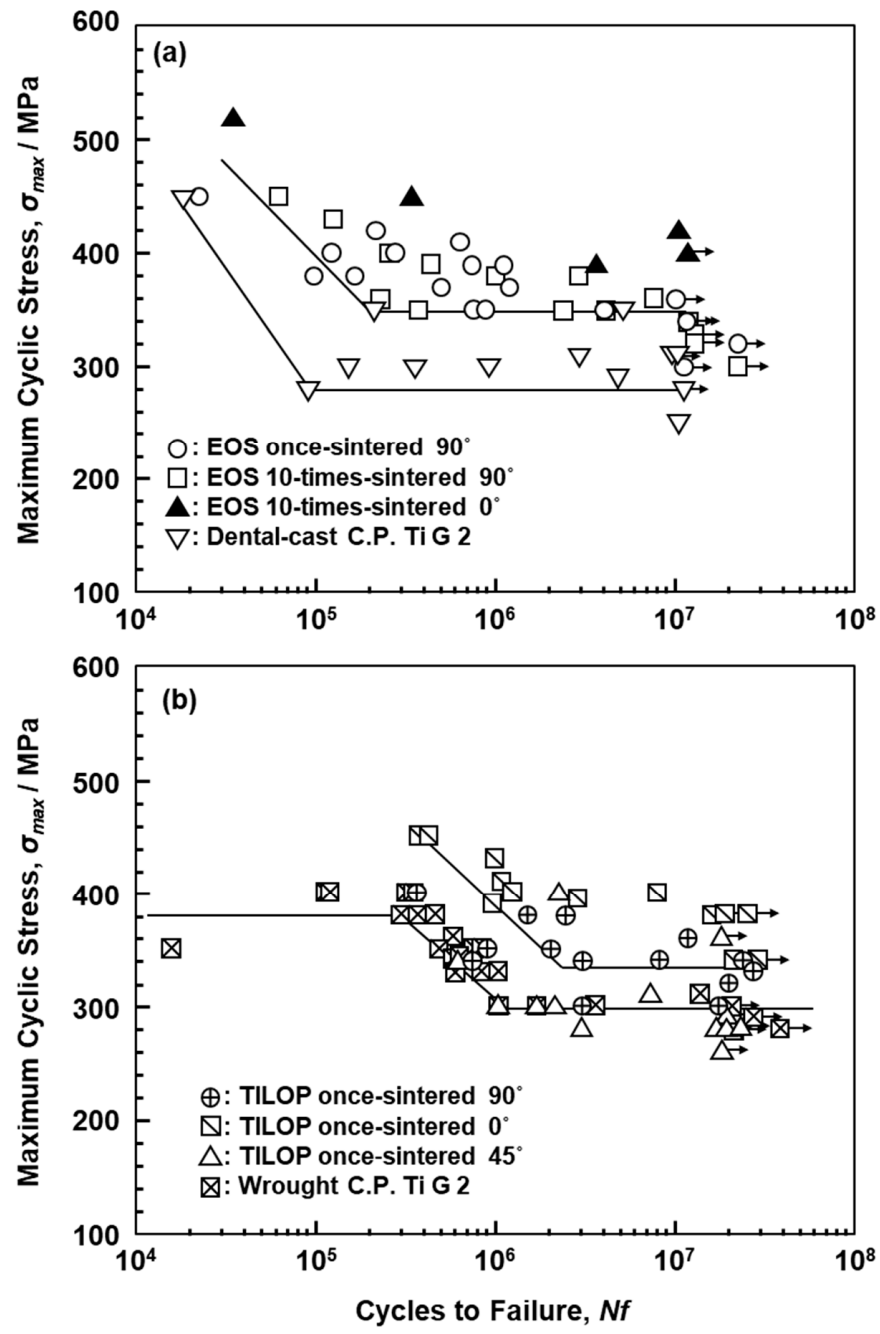

Figure 10. S-N curves of laser-sintered (a) EOS (once- and 10-times-sintered) and (b) TILOP (once-sintered) CP Ti G 2 rods; dental-cast CP Ti G 2 in (a) and wrought CP Ti G 2 in (b).

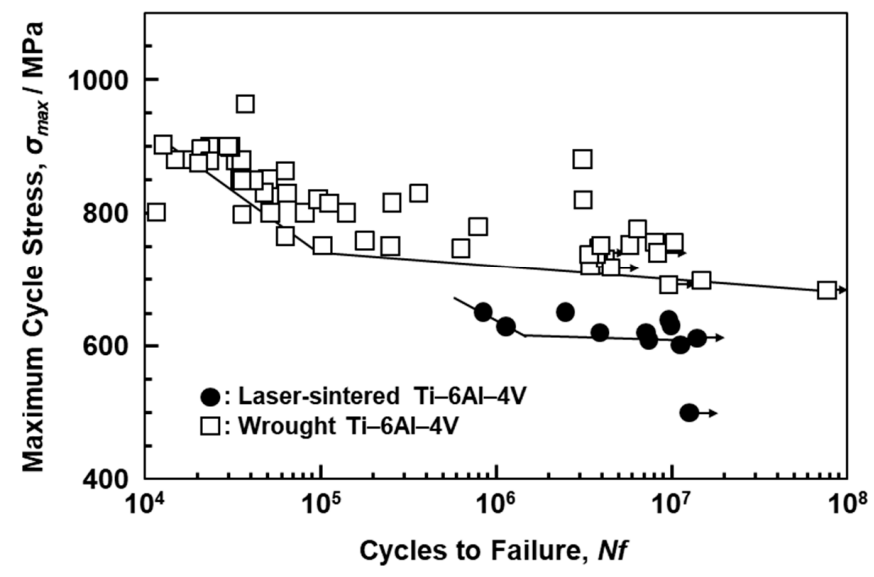

Figure 11. S-N curves of once-sintered Ti-6Al-4V alloy built in $90^{\circ}$ direction and wrought Ti-6Al-4V alloy.

Figure 12 shows SEM images of the surface of $0^{\circ}$-direction-built CP Ti G 2. A fatigue crack developed with a fatigue fracture from the periphery of the specimen, and river-like patterns and striations were observed, as shown in Figure 12e,f [38]. 

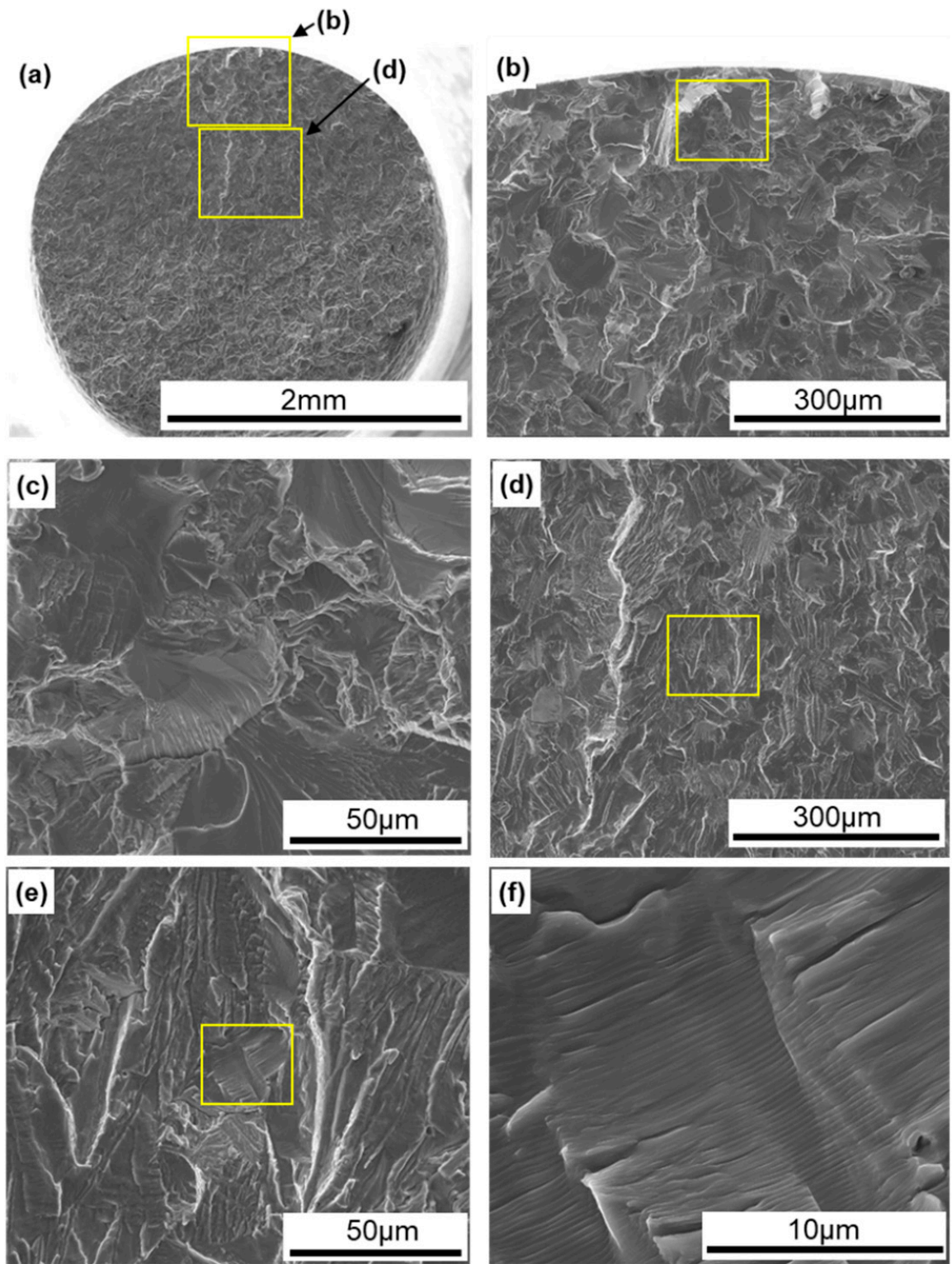

Figure 12. SEM images of fracture surfaces of fatigue-tested TILOP CP Ti G 2 (once-sintered $0^{\circ}$ ); (b) magnification of upper rectangular area in (a), (c) magnification of rectangular area in (b), (d) magnification of lower rectangular area in (a), (e) magnification of rectangular area in (d), and (f) magnification of rectangular area in (e).

It was found that the strength and ductility of CP Ti G 2 annealed at $700{ }^{\circ} \mathrm{C}$ for $2 \mathrm{~h}$ after laser sintering were excellent owing to the dispersion of fine hcp and bcc particles. AM of CP Ti materials may be a promising new manufacturing technology to replace dental Ti casting as shown in Figure 13 . The fatigue strength of the laser-sintered Ti-6Al-4V alloy was $\sim 600 \mathrm{MPa}$, which is close to that of wrought Ti-6Al-4V alloy. Therefore, laser-sintered Ti-6Al-4V alloy can also be applied in dental prostheses such as high-durability partial dentures and clasps. 


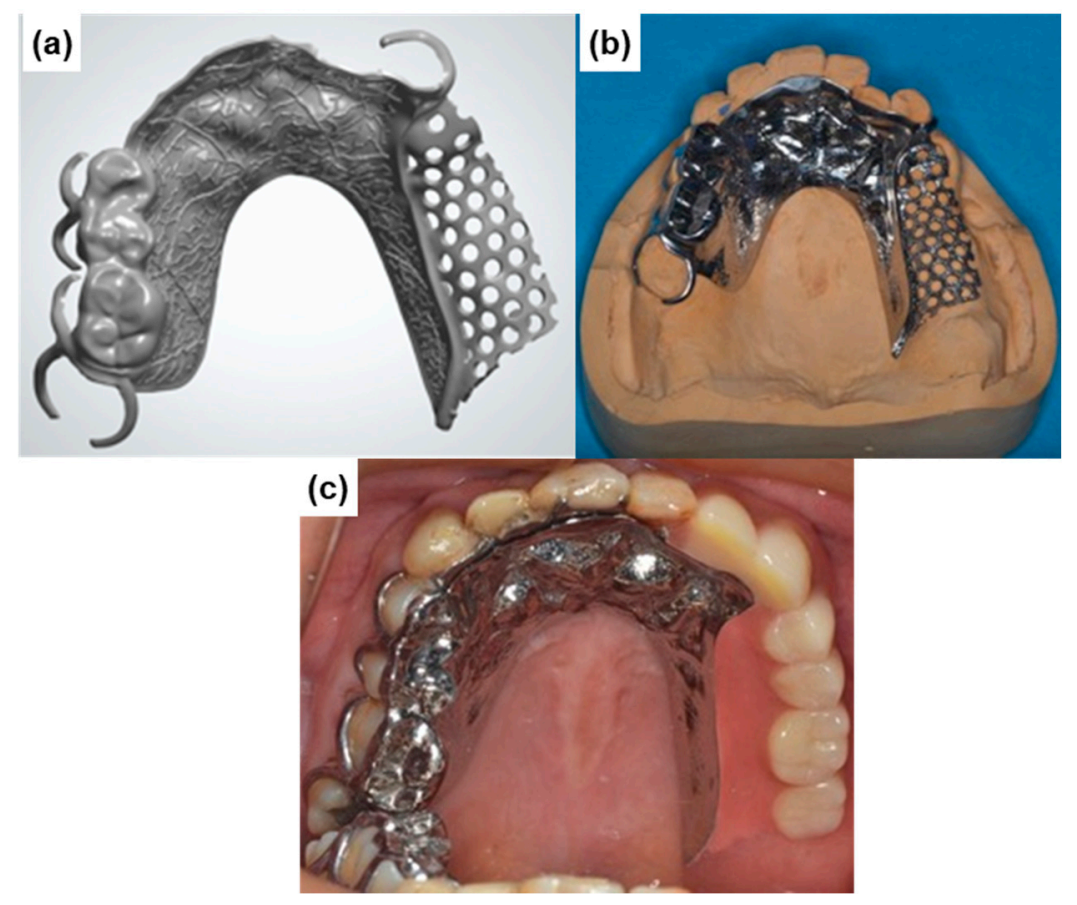

Figure 13. Partial dentures manufactured by laser sintering with CP Ti G 2 powder. (a) laser-sintered metal frame; (b) polished metal frame; (c) partial denture.

\section{Conclusions}

We evaluated the chemical composition, physical properties, microstructure, immersion property, tensile property, and fatigue strength of $\mathrm{CP}$ Ti G 2 annealed at $700{ }^{\circ} \mathrm{C}$ for $2 \mathrm{~h}$ after laser sintering and laser-sintered (as-built) Ti-6Al-4V alloy for dental applications.

The changes in the chemical composition and mechanical properties of CP Ti G 2 after laser sintering up to 10 times were negligible. The rates of Ti ion release were low, with $\mathrm{CP} \mathrm{Ti}$ and dental-cast $\mathrm{CP}$ Ti showing release rates of $1.90 \pm 0.05$ and $1.10 \pm 0.05 \mu \mathrm{g} / \mathrm{cm}^{2} /$ week, respectively.

The fatigue strengths of the $90^{\circ}-, 45^{\circ}-$, and $0^{\circ}$-direction-built CP Ti were $\sim 330, \sim 290$, and $380 \mathrm{MPa}$, respectively. The fatigue strength of the $90^{\circ}$-direction-built alloys after laser sintering 10 times was also $\sim 340 \mathrm{MPa}$. The ratios of the fatigue strength at $10^{7}$ cycles to the ultimate tensile strength $\left(\sigma_{\mathrm{FS}} / \sigma_{\mathrm{UTS}}\right)$ were $0.5-0.7$.

Precipitates identified to be bcc particles $(a=b=c=0.322 \mathrm{~nm})$ were found in the grain boundaries of the hcp matrix. The structure of the annealed CP Ti G 2 after laser sintering was similar to that of the annealed CP Ti G 2 after hot forging.

It was found that the strength and ductility of annealed CP Ti G 2 after laser sintering are excellent owing to the dispersion of the fine bcc particles. AM of CP Ti materials ( $\mathrm{G} 2$ and $\mathrm{G} 4$ ) may be a promising new manufacturing technology to replace dental Ti casting. In particular, it was clarified that laser sintering with $\mathrm{CP}$ Ti G 4 powder $(\mathrm{O} \leq 0.4$ mass \%) is useful for dental prostheses.

The fatigue strength of the laser-sintered Ti-6Al-4V alloy was $\sim 600 \mathrm{MPa}$, which is close to that of wrought Ti-6Al-4V alloy. Therefore, laser-sintered Ti-6Al-4V alloy can also be applied in dental prostheses such as high-durability partial dentures and clasps, and orthopedic implants such as artificial hip-joint stems.

Author Contributions: Mechanical tests, microstructural analysis, chemical and physical analysis, data curation, conceptualization, writing and editing of paper, Y.O.; selection of test items, regulatory approval for dental prostheses, A.I. All authors have read and agreed to the published version of the manuscript.

Funding: This research received no external funding. 
Acknowledgments: TEM analysis was supported by Kazushi Nakamura, Materials Characterization Division, Nippon Steel Technology Co., Ltd. (Chiba, Japan). Laser sintering of CP Ti G 2 rods was conducted by EOS Japan (Osaka, Japan) or Osaka Titanium Technologies Co., Ltd. (Osaka, Japan). Dental-cast CP Ti G 2 rods were cast by Wada Precision Dental Laboratories (Osaka, Japan).

Conflicts of Interest: The authors declare no conflict of interest.

\section{References}

1. Okazaki, Y.; Ishino, A.; Higuchi, S. Chemical, physical, and mechanical properties and microstructures of laser-sintered $\mathrm{Co}-25 \mathrm{Cr}-5 \mathrm{Mo}-5 \mathrm{~W}$ (SP2) and W-free Co-28Cr-6Mo alloys for dental application. Materials 2019, 12, 4039. [CrossRef] [PubMed]

2. Nakata, T.; Shimpo, H.; Ohkubo, C. Clasp fabrication using one-process molding by repeated laser sintering and high-speed milling. J. Prosthodont. Res. 2017, 61, 276-282. [CrossRef] [PubMed]

3. Takaichi, A.; Suyalatu; Nakamoto, T.; Joko, N.; Nomura, N.; Tsutumi, Y.; Migita, S.; Doi, H.; Kurosu, S.; Chiba, A.; et al. Microstructures and mechanical properties of Co-29Cr-6Mo alloy fabricated by selective laser melting process for dental applications. J. Mech. Behav. Biomed. Mater. 2013, 21, 67-76. [CrossRef] [PubMed]

4. Implants for Surgery-Metallic Materials-Part 2: Unalloyed Titanium, ISO 5832-2; International Organization for Standardization: Geneva, Switzerland, 2018.

5. Implants for Surgery-Metallic Materials-Part 3: Wrought Titanium 6-Aluminum 4-Vanadium Alloy, ISO 5832-3; International Organization for Standardization: Geneva, Switzerland, 2016.

6. O’Leary, R.; Setchi, R.; Prickett, P.; Hankins, G.; Jones, N. An investigation into the recycling of Ti-6Al-4V powder used within SLM to improve sustainability. In Proceedings of the 2nd International Conference on Sustainable Design and Manufacturing, Seville, Spain, 12-14 April 2015; pp. 377-388. Available online: http://orca.cf.ac.uk/id/eprint/81260 (accessed on 10 January 2020).

7. Standard Specification for Additive Manufacturing Titanium-6 Aluminum-4 Vanadium with Powder Bed Fusion, ASTM F 2924; American Society for Testing and Materials: West Conshohocken, PA, USA, 2014.

8. Lin, C.W.; Ju, C.P.; Lin, J.H.C. Comparison among mechanical properties of investment-cast C.P. Ti, Ti-6Al-7Nb and Ti-15Mo-1Bi alloys. Mater. Trans. 2004, 45, 3028-3032. [CrossRef]

9. Takahashi, M.; Kikuchi, M.; Takada, Y.; Okuno, O. Mechanical properties and microstructures of dental cast Ti-Ag and Ti-Cu alloys. Dent. Mater. J. 2002, 21, 270-280. [CrossRef] [PubMed]

10. Koizumi, H.; Ishii, T.; Okazaki, T.; Kaketani, M.; Matumura, H.; Yoneyama, T. Castability and mechanical properties of Ti-15Zr-5Zr-3Al alloy in dental casting. J. Oral Sci. 2018, 60, 285-292. [CrossRef] [PubMed]

11. Tamaki, Y.; Miyazaki, T. Problems on titanium castings for clinical use. J. Jpn. Prosthodont. Soc. 1998, 42, 528-539. [CrossRef]

12. Ida, K.; Togaya, T.; Tsutsumi, S.; Takeuchi, M. Effect of magnesia investments in the dental casting of pure titanium or titanium alloys. Dent. Mater. J. 1982, 1, 8-21. [CrossRef] [PubMed]

13. Collings, E.W.; Boyer, R.; Welsch, G.; Collings, E.W. (Eds.) ASM Materials Properties Handbook: Classification of Titanium Alloys; The Materials Information Society: Materials Park, OH, USA, 1994; p. 5.

14. Okazaki, Y. Development of low-cost manufacturing process and effects of adding small amounts of Ta, $\mathrm{O}$, and $\mathrm{N}$ on the physical and mechanical properties of highly biocompatible Ti alloys. Mater. Trans. 2019, 60, 1769-1778. [CrossRef]

15. Particle Size Analysis-Laser Diffraction Methods, ISO 13332; International Organization for Standardization: Geneva, Switzerland, 2009.

16. Titanium and Titanium Alloys-Determination of Hydrogen Content, JIS H 1619; Japanese Standards Association: Tokyo, Japan, 2012.

17. Methods for Determination of Nitrogen in Titanium and Titanium Alloys, JIS H 1612; Japanese Standards Association: Tokyo, Japan, 1993.

18. Methods for Determination of Oxygen in Titanium and Titanium Alloys, JIS H 1620; Japanese Standards Association: Tokyo, Japan, 1995.

19. Methods for Determination of Iron in Titanium and Titanium Alloys, JIS H 1614; Japanese Standards Association: Tokyo, Japan, 1995. 
20. Methods for Determination of Carbon in Titanium and Titanium Alloys, JIS H 1617; Japanese Standards Association: Tokyo, Japan, 1995.

21. Titanium Alloys-Methods for Determination of Aluminium, JIS H 1622; Japanese Standards Association: Tokyo, Japan, 1998.

22. Titanium Alloys-Method for Determination of Vanadium, JIS H 1624; Japanese Standards Association: Tokyo, Japan, 2005.

23. Testing Methods for Particle Density of Fine Ceramic Powder, JIS R 1620; Japanese Standards Association: Tokyo, Japan, 1995.

24. Dentistry-Corrosion Test Methods for Metallic Materials, ISO 10271; International Organization for Standardization: Geneva, Switzerland, 2011.

25. Dental Casting Cobalt Chromium Alloys, JIS T 6115; Japanese Standards Association: Tokyo, Japan, 2013.

26. Dentistry-Metallic Materials for Fixed and Removable Restorations and Appliances, ISO 22674; International Organization for Standardization: Geneva, Switzerland, 2016.

27. Metallic Materials-Tensile Testing-Method of Test at Room Temperature, JIS Z 2241; Japanese Standards Association: Tokyo, Japan, 2011.

28. Test Method for Fatigue Properties of Metallic Biomaterials, JIS T 0309; Japanese Standards Association: Tokyo, Japan, 2009.

29. Boyer, R.; Welsch, G.; Collings, E.W. (Eds.) ASM Materials Properties Handbook: Titanium Data Sheets; The Materials Information Society: Materials Park, OH, USA, 1994.

30. Okazaki, Y.; Nagata, H. Comparisons of immersion and electrochemical properties of highly biocompatible Ti-15Zr-4Nb-4Ta alloy and other implantable metals for orthopedic implants. Sci. Technol. Adv. Mater. 2012, 13, 064216. [CrossRef] [PubMed]

31. Simonell, M.; Tse, Y.Y.; Tuck, C. Microstructure of Ti-6Al-4V produced by selective laser melting. J. Phys. Conf. Ser. 2012, 371, 012084. [CrossRef]

32. Rafi, H.K.; Karthik, N.V.; Gong, H.; Starr, T.L.; Stucker, B.E. Microstructures and mechanical properties of Ti6Al4V parts fabricated by selective laser melting and electron beam melting. J. Mater. Eng. Perform. 2013, 22, 3872-3883. [CrossRef]

33. Haar, G.M.T.; Becker, T.H. Selective laser melting produced Ti-6Al-4V: Post-process heat treatment to achieve superior tensile properties. Materials 2018, 11, 146. [CrossRef] [PubMed]

34. Facchini, L.; Molinari, A.; öges, S.H.; Wissenbach, K. Ductility of a Ti-6Al-4V alloy produced by selective laser melting of prealloyed powders. Rapid Prototyp. J. 2010, 16, 450-459. [CrossRef]

35. Qiu, C.; Adkins, N.J.E.; Attallah, M.M. Microstructure and tensile properties of selectively laser-melted and HIPed laser-melted Ti-6Al-4V. Mater. Sci. Eng. A 2013, 578, 230-239. [CrossRef]

36. Vrancken, B.; Thijs, L.; Kruth, J.P.; Humbeeck, J.V. Heat treatment of Ti6Al4V produced by selective laser melting: Microstructure and mechanical properties. J. Alloys Compd. 2012, 541, 177-185. [CrossRef]

37. Gong, H.; Rafi, K.; Gu, H.; Ram, G.D.J.; Starr, T.; Stucker, B. Influence of defects on mechanical properties of Ti-6Al-4V components produced by selective laser melting and electron beam melting. Mater. Des. 2015, 86, 545-554. [CrossRef]

38. Leuders, S.; Thöne, M.; Riemer, A.; Niendorf, T.; Tröster, T.; Richard, H.A.; Maier, H.J. On the mechanical behaviour of titanium alloy TiAl6V4 manufactured by selective laser melting: Fatigue resistance and crack growth performance. Int. J. Fatigue 2013, 48, 300-307. [CrossRef]

39. Okazaki, Y.; Gotoh, E. Comparison of fatigue strengths of biocompatible Ti-15Zr-4Nb-4Ta alloy and other titanium materials. Mater. Sci. Eng. C 2011, 33, 325-333. [CrossRef]

40. Okazaki, Y. On the effects of hot forging and hot rolling on the microstructural development and mechanical response of a biocompatible Ti alloy. Materials 2012, 5, 1439-1461. [CrossRef]

(C) 2020 by the authors. Licensee MDPI, Basel, Switzerland. This article is an open access article distributed under the terms and conditions of the Creative Commons Attribution (CC BY) license (http://creativecommons.org/licenses/by/4.0/). 